Editorial

\title{
Open access journals: good or bad reading?
}

Volume 4 Issue 3 - 2016

\section{Editorial}

Open Access Journals (OAJ) initiative is not just other business in the industry of medical journals publication; it is a fast, free way to disseminate biomedical knowledge to anyone with a computer connected to internet, with the primary goal of improving mankind health. This publishing mode has caused fundamental changes in the traditional industry-printed and digital journals available only through subscriptions, site licenses or single article charges. Publishing open access commerce has evolved so much and quickly that now competes with traditional journals and books. OAJ have finally resulted in a timely dissemination of advances in science: the essence of OAJ is free access to scholarly literature without any price or permission barriers. ${ }^{1,2}$ Since the first OAJ of anesthesiology - The Internet Journal of Anesthesiology- appeared on the WEB in 1996, there has been a significant increase of free anesthesia journals on the internet. Nowadays we can search free articles on any anesthesia, critical care, pain medicine and related subjects in just a few seconds. ${ }^{3}$

Scientific medical journals can be classified in different ways. According to the availability of its content there are two large groups; traditional access payment publications and open access journals. Between these two groups of journals, there is a wide range of publications denominated as green, gold, and platinum. Those journals that require payment are published by medical societies and/ or powerful transnational publishing companies that readers have to pay annual fee or pay per article. Such pay magazines are expensive, have high manuscripts rejection rates, prolonged time for accepting and publishing manuscripts, have an enormous recognition among the scientific community, authors do not pay for their publication, nor keep their author copy right. Recently, some of these publications have selected free access issues or articles, and several pay journals have full open access several months after its original publication - this kind of partial open access is called hybrid model. ${ }^{1,4,5}$ These policies of traditional publishing companies delay diffusion of medical knowledge and finally postpone better medical attention of patients in geographic areas with fewer resources, which is where most people are sick and in need of quality health care. Doctors at these sites should be supported with recent medical information to help solve the suffering of their fellow citizens.

In order to reach a wider audience from doctors living in low income nations, in 2001 the World Health Organization made a deal with several traditional publishers to permit free access to about 7000 journals for 4800 institutions of 105 poor countries. This negotiation was named the Health Inter Network for Access to Research Initiative (HINARI), but unfortunately failed because some publishers revoked the agreement. ${ }^{6,7}$

Open access journals have two formats: PDF direct access and full access to the HTLM version with a minimum payment for the PDF version if requested. Both formats can be download, read, print and broadcast. These magazines belong to medical societies or publishing companies engaged in the business of open access publication. Most of these journals charge the authors for each publication. Authors or their financial supporters pay these duties, and the money is used to pay

\author{
Víctor Whizar-Lugo \\ Chief Editor, Intensive Care Unit, Hospital General de Tijuana, \\ ISESALUD, México
}

Correspondence: Víctor Whizar-Lugo, Intensive Care Unit, Hospital General de Tijuana, ISESALUD, Av. Centenario I085I, Zona Rio, Tijuana B.C., México, Tel +52664-6848905, Fax +52664-6848906, Email vwhizar@anestesia-dolor.org

Received: February 08, 20I6 | Published: February 10, 2016

the publishing process with a profit margin for publishers companies of open access. This policy is necessary to generate funds to keep publishing free articles. ${ }^{8,9}$ The prices have a very wide range and vary from 200 up to 1200 USD. Most open access publishing companies have waivers or low fees for researchers from low income countries, or authors who do not have financial support. India is one of the countries with the highest number of OAJ, however, the study of Singh [10] showed that only $55.6 \%$ of the 2,509 Indian health researchers included in this study had knowledge about open access model and $76 \%$ about author pay manner. Up to $76 \%$ were no interested to pay publication fees. In this study absence of research grants were the main reason for incapacity to pay.

There are OAJ linked with medical associations that have no payment fee. These kinds of journals are named Platinum OAJ and their publication expenses are cover by subsides, payments for members of societies, grants, advertisers, among others. ${ }^{11}$

There is debate on the OA scientific literature. In fact, more than a fierce debate, it looks like a war between the companies that publish prepay journals and the OAJ industry., ${ }^{72-18}$ This debate has two basic aspects; one discusses the economic topic on who is paying to publish and who pay to read. The other aspect focuses on the quality of publications. Between these two extremes are the authors, readers and more importantly, the patients. This dispute will continue forever; who is who, what is better, who is more credible?, and many more questions that for now have not adequate supported answers. Meanwhile, researchers and readers should continue to decide where to publish and what to read to improve their skills in relation to health care for their sick patients.

As a result of increased number of OAJ in all medical fields there is an exponential growth of scientific literature that makes it difficult and time consuming to decide if the published data are useful in our daily clinical practice. Until today there are more than 11,000 OAJ published in 136 countries with approximately 1.9 million articles each year. ${ }^{19}$ Most of these articles are good or excellent sources of 
information, while some are not worth to read. Unfortunately there is not an easy method to discriminate between valuable articles versus a document with little or no information at all. Therefore, as clinicians we must develop our own way to avoid reading nonsense articles, but most important, to lose free information that may help us to update our knowledge and skills. Though there are some recommendations that may facilitate us to decide to download and read a particular article: a short and descriptive title, structured abstract, a clear and short introduction, a realistic statistical analysis, a discussion with arguments related to the findings of the research that are compared with available data mentioned in the cited references. Although the authors from government hospitals in the most advanced countries have economic support for their research, many researchers from the so called developing countries with lower income, also publish useful research to improve health care.

To publish relevant animal and clinical knowledge available on the WEB under the open access model, the OAJ have to maintain the highest scientific standards, therefore OAJ can be competitive with similar journals and also compete with non-OAJ. ${ }^{8,20,21}$ OAJ listed in Web of Science and/or Scopus are approaching the same scientific influence and quality as paid subscription journals, particularly in biomedicine and for journals funded by article processing charges. ${ }^{22}$ This is not an ease goal to achieve, so in our journal, we are working our best way to assure this important goal to bring you valuable scientific information from colleagues from all over the world.

The real creator of free access to medical literature was George W Crile, a surgeon from Ohio who had the idea that biomedical information should be free when who wrote: "Yet there is no possibility of financial benefit accruing to the Founders from any research. I never cease to feel pride in the medical profession that from the earliest times a rigid code has prevented the patenting for personal profit or the keeping secret of any knowledge or instrument or method or idea that the profession has developed for the good of mankind. Every discovery is published and is as readily available to every other physician as to the discoverer himself -the theory being that medical facts have a direct bearing upon life and death, therefore in the public interest such contribution cannot be for sale". ${ }^{23}$ These concepts may be taken as the basis of the actual model of open access and free access that many current medical and non-medical journals and books use for all or part of their articles that are available for free on the WEB. In fact, the prestigious Cleveland Clinic Journal of Medicine is a publication which can be read freely since $1939 .{ }^{24}$

To end this editorial I would like to assert that OAJ facilitate prompt publication and dissemination of the received manuscripts, which is very important for authors, researchers, readers and patients. In medicine, as well in others human activities, the open access model main goal is to publish applicable information available to the worldwide community with the idea of improving the quality of our existence, to conserve our world and ensure a better future. ${ }^{2,6}$

\section{Acknowledgments}

None.

\section{Conflicts of Interset}

None.

\section{References}

1. Chatterjee P, Biswas T, Mishra V. Open access: the changing face of scientific publishing. J Family Med Prim Care. 2013;2(2):128-130.
2. Berlin Declaration on open access to knowledge in the sciences and humanities. (2003).

3. Pimm J. Open access publishing - a quiet revolution. Psychiatr Bull. 2014;38(1):1-2.

4. Abadal E. Gold or green: the debate on open access policies. Int Microbiol. 2013;16(3):199-203.

5. Ohno-Machado L. A hybrid open-access model to bridge the publishing divide and reach out to a broader community. J Am Med Inform Assoc. 2011;18(3):210-211.

6. Sarin R. Denying open access to publish health-care research: WHO has the password? J Cancer Res Ther. 2007;3(3):133-134.

7. Zachariah R, Kumar AM, Reid AJ, et al. Open access for operational research publications from low- and middle-income countries: who pays? Public Health Action. 2014;4(3):142-144.

8. Leopold SS. Paying to publish-what is open access and why is it important? Clin Orthop Relat Res. 2014;472(6):1665-1666.

9. Aguzzi A. Scientific publishing in the times of open access. Swiss Med Wkly. 2015;145:w14118.

10. Singh HP. Knowledge and attitude of health researchers from India towards paying to publish and open access journals. Indian Pediatr. 2015;52(3):252-253.

11. Fernandez-Llimos F. Collaborative publishing: the difference between 'gratis journals' and 'open access journals'. Pharm Pract (Granada). 2015;13(1):593.

12. Carroll VS. Watch out for the wolves: predatory publishing. $J$ Neurosci Nurs. 2015;47(1):1-2.

13. Hudzik B, Polonski L. Open-access.com. Int J Cardiol. 2014;171(2):284.

14. Dixon SD. The tsunami of open access. J Dev Behav Pediatr. 2014;35(2):163-164.

15. Agrawal AA. Four more reasons to be skeptical of open-access publishing. Trends Plant Sci. 2015;19(3):133.

16. Swartz MK. Open access publishing: scholarly or predatory? J Pediatr Health Care. 2015;29(2):121-122.

17. Petersen E. Open access publishing. Int J Infect Dis. 2014;25:150-151.

18. Haug C. The downside of open-access publishing. $N$ Engl $\mathrm{J} \mathrm{Med}$. 2013;368(9):791-793.

19. Dogra V. Myths about publishing in an open access journal. J Clin Imaging Sci. 2015;5:26.

20. Hong ST, Gasparyan AY. Celebrating the latest release of the journal impact factors: Thinking globally, acting locally. J Korean Med Sci. 2015;30(8):999-1000.

21. Gasparyan AY, Yessirkepov M, Voronov AA, et al. Preserving the integrity of citations and references by all stakeholders of science communication. J Korean Med Sci. 2015;30(11):1545-1552.

22. Björk BC, Solomon D. Open access versus subscription journals: a comparison of scientific impact. BMC Med. 2012;10:73.

23. Crile G. In George Crile. An Autobiography. Lippincott Company, Philadelphia, USA. 1947.

24. Whizar-Lugo VM. One century of pre-emptive and preventive analgesia. A tribute to George Washington Crile. J Anesth Crit Care Open Access. 2014;1:00032 